\title{
Wind Generation, Power System Operation and Emissions Reduction
}

\author{
E. Denny, Student Member, IEEE, M. O'Malley, Senior Member, IEEE
}

\begin{abstract}
With increasing concern over global climate change, policy makers are promoting renewable energy sources, predominantly wind generation, as a means of meeting emissions reduction targets. Although wind generation does not itself produce any harmful emissions, its effect on power system operation can actually cause an increase in the emissions of conventional plants. A dispatch model was developed which analyses the impact that wind generation has on the operation of conventional plants and the resulting emissions of Carbon Dioxide $\left(\mathrm{CO}_{2}\right)$, Sulphur Dioxide $\left(\mathrm{SO}_{2}\right)$ and Oxides of Nitrogen $\left(\mathrm{NO}_{\mathrm{X}}\right)$. The analysis concentrates on a 'forecasted' approach which incorporates wind generation forecasts in the dispatch decisions. It was found that wind generation could be used as a tool for reducing $\mathrm{CO}_{2}$ emissions but alone it was not effective in curbing $\mathrm{SO}_{2}$ and $\mathrm{NO}_{\mathrm{X}}$ emissions.
\end{abstract}

Index Terms-Wind power generation, Emission, Power system economics, Environmental factors

\section{INTRODUCTION}

D UE to concerns regarding global warming and air pollution, there has been an international movement in the promotion of renewable technologies for electricity generation and the development of national emissions limits [1]. A number of directives controlling emissions are currently in place which have particular impact on the electricity industry, such as the Kyoto Protocol [2], the Large Combustion Plant Directive [3] and the National Emissions Ceilings Directive [4]. As wind generation does not itself create any harmful emissions, policy makers often promote it as a means to reduce a country's national emissions levels. However, it is unclear whether policy makers consider the effects that large levels of wind generation have on system operation. A system operator's primary objective is to maintain a secure and reliable electricity supply, however, a large penetration of unpredictable and variable generation introduces additional constraints on the system. Any imposed constraint on system operation will result in an increase in operation costs and may have a detrimental effect on emissions.

In order to accommodate the variability of the wind generation a system operator may decide to operate a number of combustion plants at lower operating levels to be available to ramp up should the wind generation drop off. With certain generator types, emissions per MW increase when the generator's

This work has been conducted in the Electricity Research Centre, University College Dublin which is supported by Electricity Supply Board (ESB) Networks, ESB Power Generation, ESB National Grid, Commission for Energy Regulation, Cylon, Airtricity and Enterprise Ireland.

E. Denny and M. O'Malley are with the Department of Electronic and Electrical Engineering, University College Dublin, Dublin 4, Ireland (Ph: +353 (0)1 7161857; e-mail: eleanor.denny@ucd.ie; mark.omalley@ucd.ie). load is reduced [5]. With increasing levels of wind penetration combustion plants may be required to ramp up and down more frequently to accommodate the unpredictable variability in the wind generation [6]. Emissions increases are also apparent during ramping and starting up of combustion plants. Thus, it may be the case that some of the environmental benefits of wind generation may be negated by an increase in emissions from combustion plants accommodating the wind generation. The extent of this impact will depend predominantly on the plant mix in the system. As discussed in [7] even a demand side involvement in system operation can have a detrimental effect on emissions given a particular plant mix.

This paper will analyse the effect that wind generation has on emissions from generation plants under certain system operation scenarios. Section II outlines the processes by which $\mathrm{CO}_{2}, \mathrm{SO}_{2}$ and $\mathrm{NO}_{\mathrm{X}}$ are formed in the combustion of different fuels. Section III describes briefly alternative system operation approaches with wind generation, details the dispatch model and outlines some of the assumptions used in the study. The results and discussions for sample years 2003 and 2010 for a real power system along with certain scenarios are summarised in Section IV. The conclusions are given in Section V.

\section{EMission CREATION IN COMbustion Plants}

Carbon Dioxide is generated by the combustion of fuels containing carbon. The amount of carbon dioxide released is in direct proportion to the amount of carbon in the fuel and the quantity of fuel burnt. Thus a generation plant which burns a carbon intensive fuel will generate more carbon dioxide at increased levels of operation.

Sulphur (S) is found in hydrocarbon fuels and is mostly in pure form. Given the high temperatures and oxygen concentrations during combustion, sulphur dioxide $\left(\mathrm{SO}_{2}\right)$ is the principal sulphur compound formed in combustion [8]. As a result, the analysis that follows will concentrate on emissions of $\mathrm{SO}_{2}$ rather than alternative sulphur compounds.

Oxides of Nitrogen $\left(\mathrm{NO}_{\mathrm{X}}\right)$ are formed by the combination of nitric oxide (NO) and nitrogen dioxide $\left(\mathrm{NO}_{2}\right)$. $\mathrm{NO}$ and $\mathrm{NO}_{2}$ are formed during combustion by the reaction of nitrogen present in the combustion system, either in the fuel or in the combustion environment. Normally $\mathrm{NO}$ is formed in much larger amounts than $\mathrm{NO}_{2}$, and $\mathrm{NO}_{2}$ is formed by further reaction of NO [9]. Thus, NO formation determines the total amount of $\mathrm{NO}_{\mathrm{X}}$ emitted. Unlike $\mathrm{CO}_{2}$ and $\mathrm{SO}_{2}, \mathrm{NO}_{\mathrm{X}}$ formation does not depend solely on the nitrogen content of the fuel. It is also significantly affected by the flame temperature, the oxygen concentration and the residence time. The formation 
of $\mathrm{NO}_{\mathrm{X}}$ can be attributed to four distinct chemical kinetic processes: thermal $\mathrm{NO}_{\mathrm{X}}$ formation, prompt $\mathrm{NO}_{\mathrm{X}}$ formation, fuel $\mathrm{NO}_{\mathrm{X}}$ formation and reburning [10].

\section{A. Coal, Heavy Fuel Oil Generators and Peat}

As described above, the carbon dioxide and sulphur dioxide emissions from a generation plant depend on the chemical content and the calorific value of the fuel. Coal typically has a carbon content of about $65 \%$ and a calorific value of $26 \mathrm{MJ} / \mathrm{kg}$ and heavy fuel oils have a carbon content of about $87 \%$ and a calorific value of $40 \mathrm{MJ} / \mathrm{kg}$ [11]. Heavy fuel oils usually contain higher amounts of sulphur than other petroleum products as sulphur tends to concentrate in the residue during the refining processes [12]. Low sulphur heavy fuel oil has a lower sulphur content, about 0.5 - 1.0\% compared to $2 \%$ for standard heavy fuel oils. Fuel $\mathrm{NO}_{\mathrm{X}}$ is the major source of $\mathrm{NO}_{\mathrm{X}}$ emissions from the combustion of nitrogen bearing fuels such as heavy oils, coal and peat ${ }^{1}$ [14].

\section{B. Gas Fired Generators}

The typical carbon content of natural gas is $70 \%$ with a calorific value of approximately $48 \mathrm{MJ} / \mathrm{Nm}^{3}$. Natural gas contains a negligible amount of sulphur, thus emissions of $\mathrm{SO}_{2}$ are not significant for gas turbines [11]. Thermal $\mathrm{NO}_{\mathrm{X}}$ is the predominant source of $\mathrm{NO}_{\mathrm{X}}$ emissions from a gas turbine. Due to the increasing number of gas fired generation plants on electricity systems, and their unique $\mathrm{NO}_{\mathrm{X}}$ characteristics, the formation of $\mathrm{NO}_{\mathrm{X}}$ in a gas turbine will be outlined in more detail below.

Thermal $\mathrm{NO}_{\mathrm{X}}$ is formed by reactions known as the Zeldovich mechanism. These reactions determine the rate of thermal $\mathrm{NO}_{\mathrm{X}}$ which becomes significantly faster at high temperatures. NO can be minimised by reducing the concentration of $[\mathrm{O}],\left[\mathrm{N}_{2}\right]$ and by reducing the temperature [15], however, reducing the flame temperature reduces the efficiency of the plant.

In order to achieve reduced emissions, gas turbine manufacturers have adopted lean premixed combustion as a standard technique. This premix (of fuel and air) achieves low levels of pollutant emissions without the need for additional hardware for steam injection or selective catalytic reduction. By premixing the fuel and air prior to firing, localized regions of near stoichiometric fuel-air mixtures are avoided and a subsequent reduction in thermal $\mathrm{NO}_{\mathrm{X}}$ can be realized [16]. Lean premixed combustion is limited by the presence of combustion instabilities, which induce high pressure fluctuations, which can produce turbine damage, flame instability and even flame extinction [17]. For this reason the fuel and air premix is not possible during startup and at reduced load levels (below about $65-70 \%$ of maximum capacity). As a result, $\mathrm{NO}_{\mathrm{X}}$ emissions in a Combined Cycle Gas Turbine (CCGT) and an Open Cycle Gas Turbine (OCGT) increase significantly at lower loads (see Fig. 1).

\footnotetext{
${ }^{1}$ Peat is made up of partially decomposed plant debris and is considered an early stage in the development of coal. Peat is distinguished from lignite by the presence of free cellulose and a high moisture content (exceeding 70\%) [13].
}

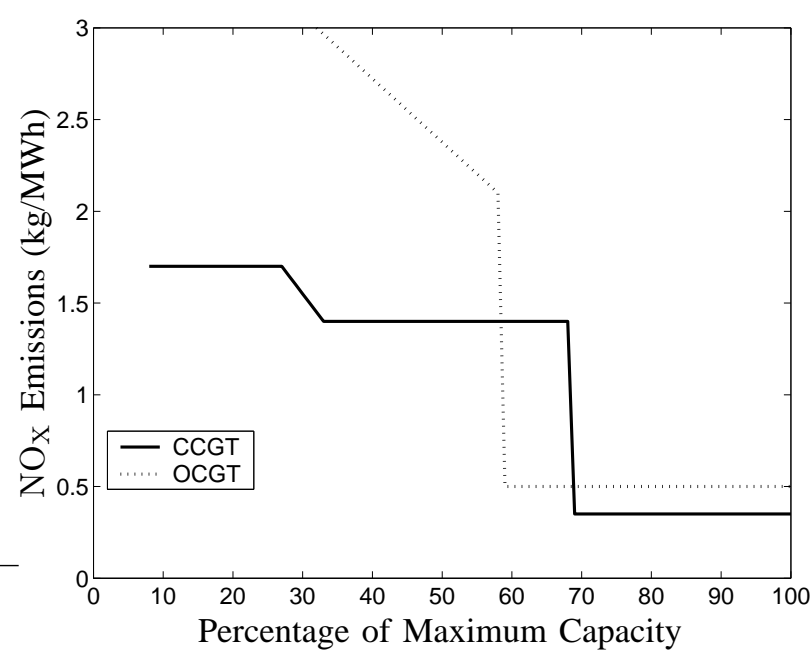

Fig. 1. Typical $\mathrm{NO}_{\mathrm{X}}$ Emissions from a Combined Cycle Gas Turbine and an Open Cycle Gas Turbine [5]

From Fig. 1 it is clear that if a CCGT is forced to operate below approximately $70 \%$ or an open gas cycle gas turbine below $60 \%, \mathrm{NO}_{\mathrm{X}}$ emissions per $\mathrm{MW}$ will increase significantly.

\section{THE IMPACT OF WIND GENERATION ON ELECTRICITY SYSTEM OPERATION}

Due to its relatively unpredictable and variable nature, wind generation can cause significant issues for system operators. Two system operation approaches have been investigated in this study. The first is known as the fuelsaver approach and under this approach wind generation is not considered in the scheduling of the plants. The second approach is known as the forecasted approach and this operation strategy incorporates wind generation forecasts into the scheduling decisions.

Previous studies analysing the system impacts of wind generation have concentrated on the fuelsaver approach (see [18], [19]). Under this approach, wind generation is not considered in the scheduling of the plants and the unit commitment decisions are made ignoring any installed wind capacity. Once the scheduling decision has been made, the wind generation is considered. If wind generation is available it is used and marginal conventional plants which were dispatched are deloaded to accommodate the wind generation. A conventional plant can be deloaded as far as its minimum but no plants are switched off. If wind production reaches a level such that no more conventional generation can be deloaded, then any further wind production is curtailed. This operational strategy considers that the only benefit of wind generation is a fuelsaving one and it assumes that wind generation has a capacity value of zero. This is a simplistic approach and it allows issues of forecasting and reliability of wind production along with some issues of system dynamics to be ignored. An alternative operation approach, the forecasted approach is studied here. Under this operational strategy wind forecasts are included in the dispatch decisions [20]. As a result fewer plants are dispatched and are run at higher efficiencies than under the fuelsaver approach. 


\section{A. The Dispatch Model}

The dispatch model used in this analysis aims to represent a deregulated market where central unit commitment algorithms are not used and market participants are expected to selfcommit. The model is an economic dispatch model which aims to dispatch the system in a least-cost manner subject to constraints. To achieve this least-cost solution, a linear programming market clearing formulation is used to co-optimise unit operating points and reserve levels on an hourly basis. Generators are assumed to have linear, cost reflective bids for energy and reserve. The aim is to minimise the following objective function:

$$
\min \left(\sum_{i=1}^{N} c p_{i} P_{i}+\sum_{i=1}^{N} c r_{i} R_{i}\right)
$$

where $P_{i}$ is the power from unit $i$, and hence the size of the contingency on loss of unit $i$, and $R_{i}$ is the primary reserve from unit $i$. The energy and reserve bids of generator $i$ are given by $c p_{i}$ and $c r_{i}$ respectively and $N$ is the number of generators. If losses are neglected then the minimisation is subject to a load balancing constraint and a reserve target (R).

$$
\begin{gathered}
\sum_{i=1}^{N} P_{i}=\mathrm{Load} \\
\sum_{i=1}^{N} R_{i} \geq \mathrm{R}
\end{gathered}
$$

The characteristics for each unit $i$ are given by equations (4) to $(7)$.

$$
\begin{gathered}
0 \leq P_{i} \leq P \max _{i} \\
0 \leq R_{i} \leq R \max _{i} \\
P_{i}-\frac{1}{R \operatorname{slope}_{i}} R_{i} \leq P \max _{i} \\
\frac{-R \max _{i}}{P \min _{i}} P_{i}+R_{i} \leq 0
\end{gathered}
$$

The nature of the reserve characteristics for the units is illustrated in Fig. 2.

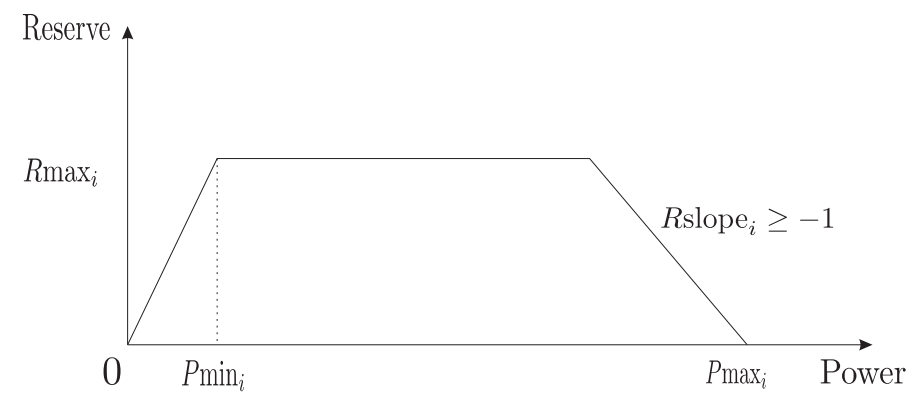

Fig. 2. Generator reserve characteristics
Reserve targets are based on [21] where there is a base case tertiary reserve target equal to the size of the largest unit and an increasing reserve target with increased installed wind generation. This increase in the reserve target is derived by taking into account wind power forecast errors, load forecast errors, system reliability criteria and forced outage probabilities [21].

Discrete decisions must be made about the on/off status of a generator to ensure it is not dispatched in its infeasible region $0<P_{i}<P \min _{i}$. Since the dispatch model does not explicitly contain discrete decision variables, the following approach was adopted. The model is first run with the feasible set of $P_{i}$ permitted to fluctuate between 0 and $P \max _{i}$ (4). This will result in optimality but not necessarily feasibility as some units may be dispatched below their minimum operating point, $P \min _{i}$. Given linear bids for energy and reserve, and the nature of the constraints, it is assumed that those units which have been dispatched below their minimum are necessary for load balance (2). Thus, the algorithm is run a second time with all units that were deemed necessary for the dispatch turned on. This is done by constraining $P_{i}, P \min _{i} \leq P_{i} \leq$ $P \max _{i}$. The remainder of the units are made unavailable. The algorithm now returns a feasible dispatch. Further details can be found in [22].

This simple approach can potentially result in surplus generation, however, on multiple runs, it was found that this methodology gave only a very slight increase in the value of the objective function between the first and second run of the algorithm. Results were also compared to a unit commitment algorithm, available within the PLEXOS environment [23]. After multiple comparative runs, the mean absolute error of the annual emissions from the dispatch model compared to the unit commitment model was less than $0.5 \%$ for $\mathrm{CO}_{2}$ and $\mathrm{SO}_{2}$. The dispatch model underestimates the $\mathrm{NO}_{\mathrm{X}}$ emissions by approximately $10 \%$ due to the dispatch algorithm not having the ability to deal with temporal constraints, mainly minimum up times. However, the impact of wind generation on the $\mathrm{NO}_{\mathrm{X}}$ emissions was quantitatively the same regardless of which model was used, i.e. the same reduction/increase was observed. As the objective of this study is to investigate emissions reduction, the dispatch model was deemed appropriate.

\section{B. Pumped Storage}

In the system analysed in Section IV, there is one large 292MW pumped storage station which plays a critical role in system security. It pumps during the night in order to be available for reserve during the night and for energy and reserve during the day. It is also used to maintain the operation levels of cheap, inflexible base-loaded plant at night. Given the different start-up times of various plants on the system, the pumped storage station is often used to start-up some plants so they will be available for energy and reserve during the day. The dispatch model based the operation of this pumped storage station on historical dispatches [24].

\section{Wind Generation}

The assumed wind generated on any day was based on ten years of real data from Irish wind farms [5], [24]. Wind 
generation does not follow a predictable profile each day, so for each sample day simulated a range of possible wind profiles were generated based on real historical data for the month in which the sample day occurred. A wind profile was then chosen at random from the range given. These profiles spanned from some days with particularly low wind generation to some days with particularly high wind generation. Fig. 3 illustrates the actual wind profiles on 5 sample days in June 2003.

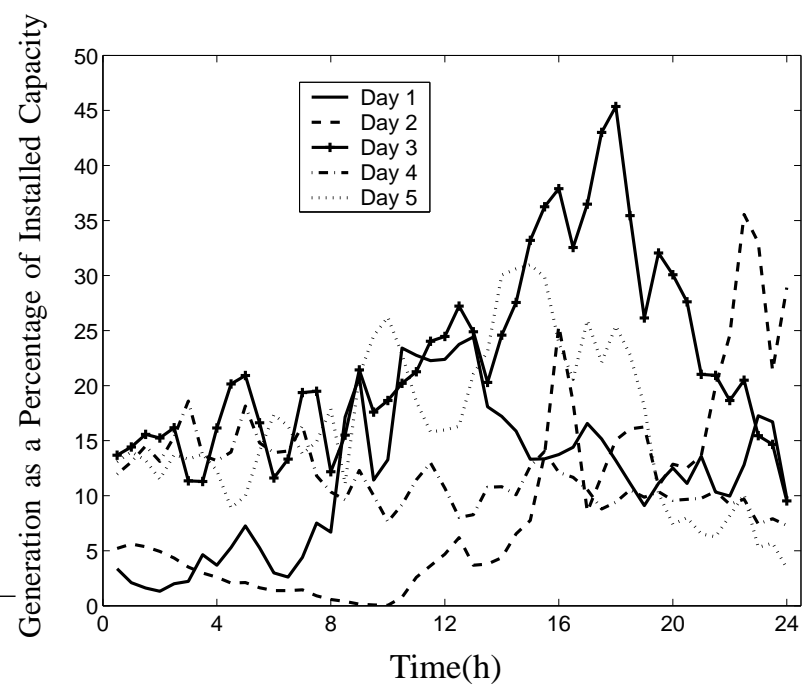

Fig. 3. Actual wind profiles on five sample days in June 2003 [24]

It can be seen from Fig. 3 that over a small number of days, the wind generation was seen to peak at different times of the day and displayed different levels of wind output. In the dispatch model, wind turbine availability was assumed to be $90 \%$.

Under the fuelsaver approach the algorithm is run with the installed wind capacity set to equal zero. Once a feasible dispatch had been determined, a suitably scaled wind profile is selected at random as described above. Those plants which were dispatched by the model are then deloaded to accommodate the assumed wind generation, starting with the most expensive unit.

When the model is run using the forecasted approach, the wind generation 'bids' into the dispatch model, with an assumed bid price of $€ 0.01 / \mathrm{MWh}$. This ensures that the forecasted wind generation is always the cheapest unit and is thus always accepted in the dispatch decision (in line with the EU Directive on the preferential treatment of renewable generation [1]).

To investigate the impact of daily wind forecast errors on emissions, the model was run with the forecasted wind profile for the first run of the algorithm (as described in III-A). This determines which generators are dispatched. Before the second run of the algorithm, the wind profile was changed to an 'actual' wind profile. The 'actual' wind profile was generated by manipulating the forecasted wind profile using random numbers generated by a Gaussian probability distribution with standard deviations of wind forecasts errors as given in [21]. It was found that the difference in annual emissions between the model run in its entirety with the 'forecasted' wind profile and then as described above was negligible. The mean squared error of annual emissions between the 'forecasted' and 'actual' scenario was $0.3 \%$ for $\mathrm{CO}_{2}, 0.5 \%$ for $\mathrm{SO}_{2}$ and $0.5 \%$ for $\mathrm{NO}_{\mathrm{X}}$. Therefore, for any sample day chosen, a perfect wind forecast is assumed as the overestimation of emissions on days of under forecasting will be balanced by underestimations on other days.

\section{Emissions Calculations}

Once a feasible dispatch has been attained using the model described above, the resulting $\mathrm{CO}_{2}, \mathrm{SO}_{2}$ and $\mathrm{NO}_{\mathrm{X}}$ emissions from the conventional units are calculated for each hour by using specific emissions information for each individual generator [5]. It was assumed that the $\mathrm{CO}_{2}$ and $\mathrm{SO}_{2}$ values did not change significantly during ramping. However, due to the increased $\mathrm{O}_{2}$ levels present during ramping, a $10 \%$ increase over steady state conditions was applied at various loads to capture the potential $\mathrm{NO}_{\mathrm{X}}$ increases during periods of significant ramping [5].

\section{Results \& Discussion}

The chosen test system for this study is Ireland since it is a small island system with limited interconnection and a relatively large and growing installed wind capacity (currently representing 3.3\% of total installed capacity). The Irish electricity system is made up of two separately operated but interconnected systems, one in the Republic of Ireland and one in Northern Ireland. This paper studies an 'all Ireland' electricity system, covering the Republic of Ireland and Northern Ireland (referred to jointly in this paper as 'Ireland'). It has an installed capacity of almost 7,000MW and one HVDC interconnector to Scotland. Ireland has a large wind power resource, however, its relatively small and weakly interconnected nature makes security issues particularly challenging compared to other systems. Installed capacity of wind generation in the Republic of Ireland as of December 2003 was 353MW [25]. Ireland is unique in having a large natural peat resource and peat fired generation accounts for approximately 350MW of Ireland's installed capacity [24]. The base case tertiary reserve target for Ireland is assumed to be $420 \mathrm{MW}$. For installed wind generation less than $500 \mathrm{MW}$ there is a minimal increase in the base case tertiary reserve target. Above 500MW, it was assumed the reserve target increased by $10 \mathrm{MW}$ for every $100 \mathrm{MW}$ installed of wind generation [21].

Load values for the Republic of Ireland are from the Irish transmission system operator [24]. The Northern Ireland electricity system is about one third of the size of the system in the Republic of Ireland so the load values for the Republic were scaled up by a factor of 1.33 to represent the two systems. To generate results for an entire year, the model was run for a sample business day and a non business day for each month and then scaled up to give the results for an entire year. To analyse the system in the year 2010, load was assumed to be 1.25 times the current load [25].

It is important to note at this stage that although wind generation has an impact on emissions, the extent of this impact is largely due to the plant mix available. As discussed 
in [7], the emissions savings to be gained by an alteration to the status-quo system operation is predominantly dependent on the plant fuel type to be affected by this change. Thus, the effects of wind generation in a system with a large installed capacity of coal and oil plants for example will differ significantly from the same level of installed capacity in a system with a predominance of gas fired plant.

Fig. 4 illustrates emissions for a sample business day (Day 5 from Fig. 3) under a fuelsaver and a forecasted scenario against various installed wind capacities. The emissions under each approach are expressed as a percentage of the emissions on the sample day with no wind generation. The assumed installed capacity of conventional generation and emission characteristics of Irish plant is as it was in 2003.
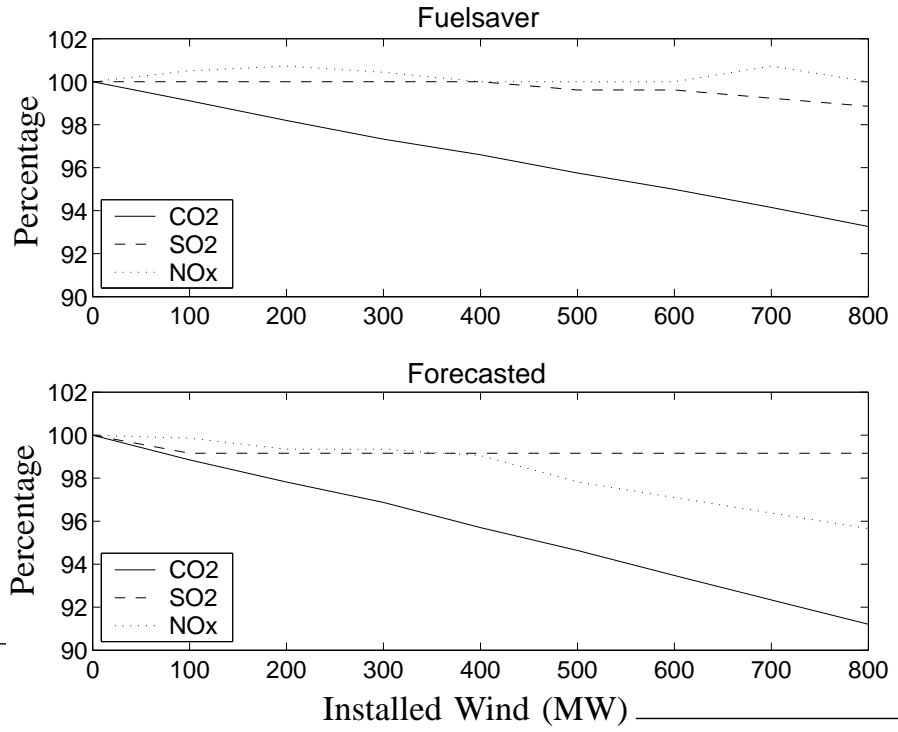

Fig. 4. Emissions under fuelsaver and forecasted approaches compared to a no wind day for a sample business day in 2003

It is clear from Fig. 4 that although wind generation offers emissions savings, the relationship between installed wind levels and emission reductions is non-trivial. Under the fuelsaver system operation approach it was found that even with large levels of wind penetration there were minimal emissions savings over a 'no wind' scenario for $\mathrm{SO}_{2}$ and $\mathrm{NO}_{\mathrm{X}}$. It was found that in some cases the national $\mathrm{NO}_{\mathrm{X}}$ emissions actually increased with increasing wind generation operated in a fuelsaver environment, for example moving from $600-700 \mathrm{MW}$ installed capacity. This was due in part to the characteristics of the CCGTs as described in Section II-B Fig. 1. It is also evident that if reduction of $\mathrm{SO}_{2}$ emissions is a policy objective then increasing wind generation may not be an ideal policy instrument under either scenario. This is because the heaviest $\mathrm{SO}_{2}$ polluters in Ireland are the base-loaded coal and peat plants whose operation levels are not affected by changes in wind or load.

The forecasted approach shows greater emissions savings across all emissions when compared with the fuelsaver approach. This is because fewer plants are operating and are running at higher efficiencies than under the fuelsaver approach. For the fuelsaver approach an installed wind capacity of $800 \mathrm{MW}$ (representing over $11 \%$ of the national installed generation capacity) resulted in only a $6.5 \%$ reduction in $\mathrm{CO}_{2}$, whereas the same installed capacity of wind generation operated under a forecasted approach resulted in a $9 \%$ decrease. As a result, the following analysis will concentrate on the forecasted approach due to the under-performance of the fuelsaver approach across all emissions.

Under the forecasted approach the $\mathrm{CO}_{2}$ reduction appeared to be in approximately a 1:1 relationship with the increasing wind levels. For $\mathrm{SO}_{2}$ and $\mathrm{NO}_{\mathrm{X}}$ the relationship was not so simple. In order to understand further this relationship Fig. 5 illustrates the correlation between the load levels, the wind profile and the emissions of $\mathrm{CO}_{2}, \mathrm{SO}_{2}$ and $\mathrm{NO}_{\mathrm{X}}$ for the sample business day used in Fig. 4. The installed wind capacity is assumed to be $300 \mathrm{MW}$ and is operated under a forecasted approach. Each variable has been plotted against its maximum value to illustrate its fluctuations throughout the day.

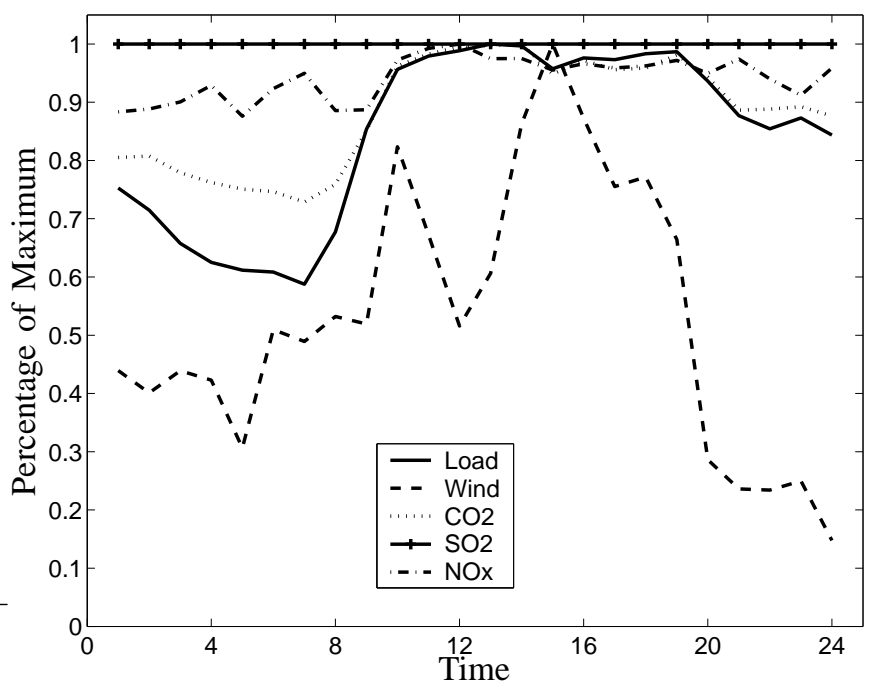

Fig. 5. Relationship between daily load and emission fluctuations for a sample day in 2003

As expected $\mathrm{CO}_{2}$ largely follows the load throughout the day with increasing loads requiring increased generation and hence increased $\mathrm{CO}_{2}$ emissions. It is also clear that $\mathrm{SO}_{2}$ emissions remain largely unaffected by variations in the wind or the load due to the base loaded coal and peat plants. $\mathrm{NO}_{\mathrm{X}}$ emissions appear to be most volatile during the night and early morning. This is a period of low load and relatively low wind. During this period, the large 292MW pumped storage station is pumping and a number of gas plants are dispatched to operate at a lower efficiency to be available for reserve. This clearly illustrates that regardless of the installed capacity of wind generation, there exist significant system operation factors which affect the $\mathrm{NO}_{\mathrm{X}}$ emissions levels and any possible $\mathrm{NO}_{\mathrm{X}}$ emission savings from wind generation may be inhibited by such system operation constraints.

The model was then run for the year 2010. By 2010 it is expected that a number of new CCGT plants will have been built in Ireland and under the Large Combustion Plant Directive and the National Emissions Ceiling Directive many existing installations will have installed emission abatement 
technologies by this year. Under the EU Directive [1] the Republic of Ireland must generate $13.2 \%$ of its gross electricity consumption through renewable energy sources by 2010 . Given load projections in the ESB's Generation Adequacy Report [26] and an assumed capacity factor of 33\%, installed renewable energy in the Republic needs to be approximately $1500 \mathrm{MW}$ in 2010 to meet this renewable target. This is a highly ambitious target considering the current installed capacity of renewable energy in the Republic of Ireland is approximately 353MW [25]. Fig. 6 shows the resulting annual emissions with varying levels of installed wind generation under a forecasted approach for 2010.
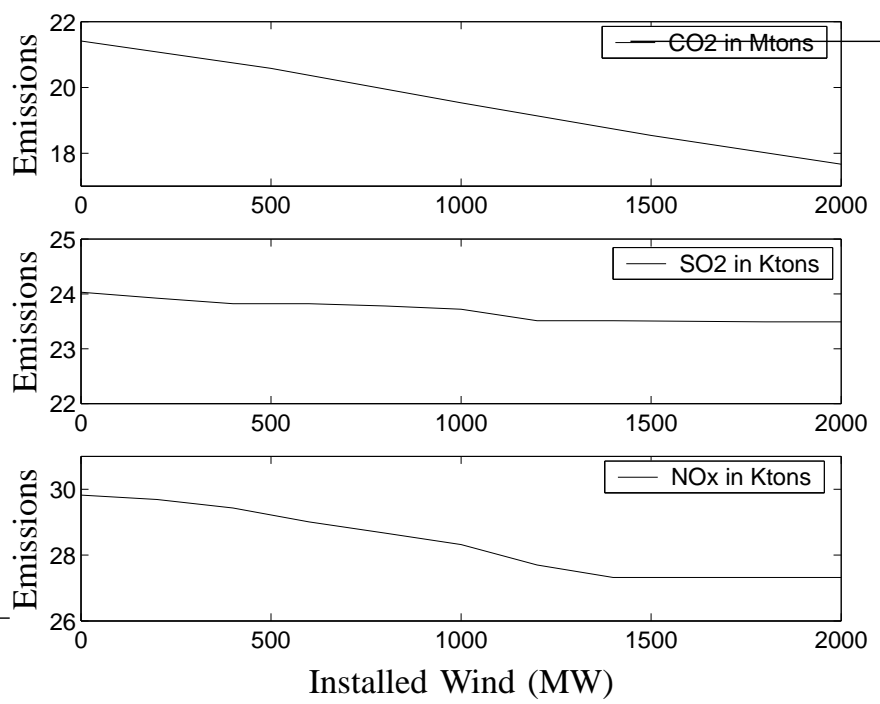

Fig. 6. Annual emissions in 2010 with varying installed wind levels

Fig. 6 clearly shows that although wind generation can aid in the reduction of $\mathrm{CO}_{2}$ emissions it may not be an appropriate measure to reduce emissions of $\mathrm{SO}_{2}$ and $\mathrm{NO}_{\mathrm{X}}$. The benefit of wind generation for the reduction of emissions of both $\mathrm{SO}_{2}$ and $\mathrm{NO}_{\mathrm{X}}$ is minimal and further investment in wind generation has little effect on emission reductions.

In an attempt to reduce $\mathrm{SO}_{2}$ and $\mathrm{NO}_{\mathrm{X}}$ emissions, a number of other scenarios were investigated. An alternative approach to reducing emissions is to dispatch the system while incorporating an emissions cost into generators' marginal costs. A tax on carbon of $€ 20$ per ton of $\mathrm{CO}_{2}$ (central scenario in [27]) was incorporated into the marginal cost of the generators and the system was dispatched accordingly. This showed significant emission savings across each of $\mathrm{CO}_{2}, \mathrm{SO}_{2}$ and $\mathrm{NO}_{\mathrm{X}}$. Fig. 7 below compares the results from the base case shown in Fig. 6 (solid line) and the results when wind is combined with a carbon tax (broken line).

It is evident from Fig. 7 that when wind is combined with a carbon tax, emission reductions are much greater and are more highly correlated with installed wind. This is due to the carbon tax altering the merit order. Thus, although wind alone may not be the best solution to reduce emissions, when combined with a carbon tax, reduced emissions are apparent across each of $\mathrm{CO}_{2}, \mathrm{SO}_{2}$ and $\mathrm{NO}_{\mathrm{X}}$.

For security of supply reasons the Irish Government made
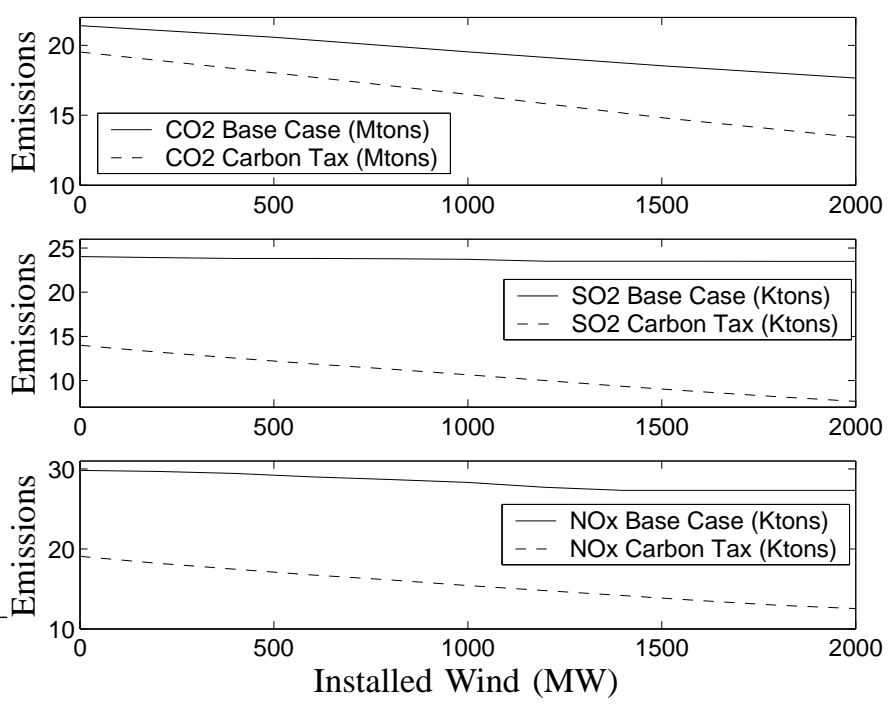

Fig. 7. Annual emissions in 2010 with varying installed wind levels and a Carbon Tax of $€ 20$

a policy decision to adopt a 'must run' approach for all peat fired generators. The inefficient and high emitting peat is then subsidised by a Public Service Obligation on all electricity bills [28]. A scenario was run where this 'must run' feature of peat was removed and the peat plants were required to 'bid' their marginal cost [5] like all other plants. Fig. 8 compares the emissions in 2010 with varying levels of installed wind capacity under the base case shown in Fig. 6 (solid line) with the situation where peat must 'bid' into dispatch model (broken line).
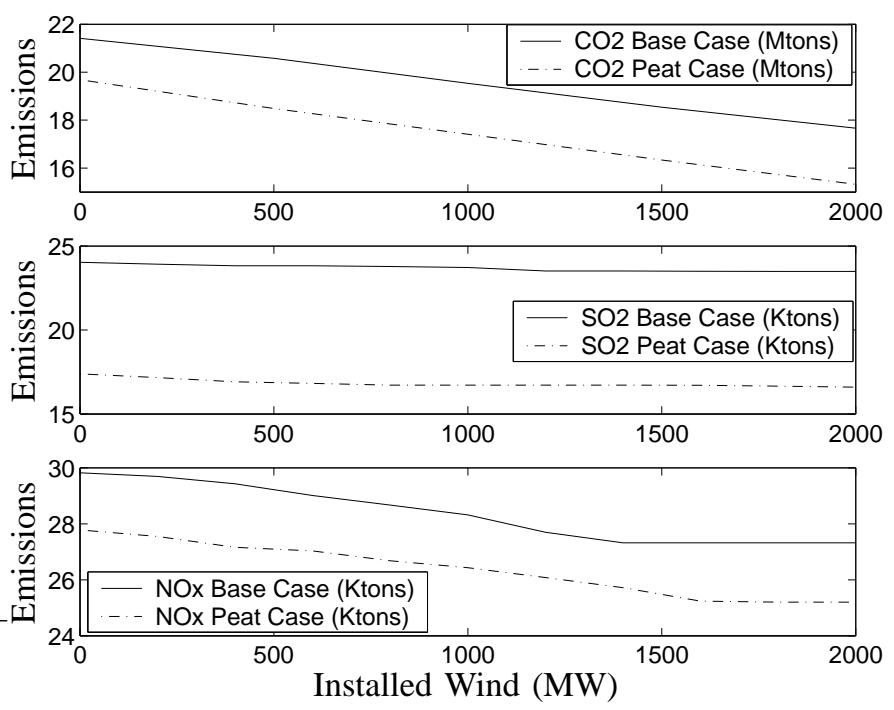

Fig. 8. Annual emissions in 2010 with alternative peat scenarios

From Fig. 8 it can be seen that when wind is combined with a strategy of non-preferential treatment towards peat there are significant emission savings of $\mathrm{SO}_{2}$. Carbon dioxide and $\mathrm{NO}_{\mathrm{X}}$ emissions are also reduced but to a lesser extent over the case where peat is treated as 'must run'.

Intuitively the most efficient and cheapest way to reduce emissions is to reduce the load. Despite the continuing eco- 
nomic growth in Ireland, energy consumption is beginning to decouple from economic growth [29]. The model was thus run for the year 2010 to compare the emissions savings of a load decrease compared to an increase in wind generation. An installed capacity of $800 \mathrm{MW}$ of wind generation was assumed and the emissions were calculated on each model run with the load decreasing in increments of 10MW. The process was then repeated for the same year, however, this time instead of reducing the load, the installed wind generation was increased in increments of 10MW. Fig. 9 below compares the additional wind generation (above $800 \mathrm{MW}$ ) that would be required to equal the emissions reductions from a decrease in the load over the year. $\mathrm{SO}_{2}$ emissions are not included given the minimal $\mathrm{SO}_{2}$ savings with increasing levels of installed wind.

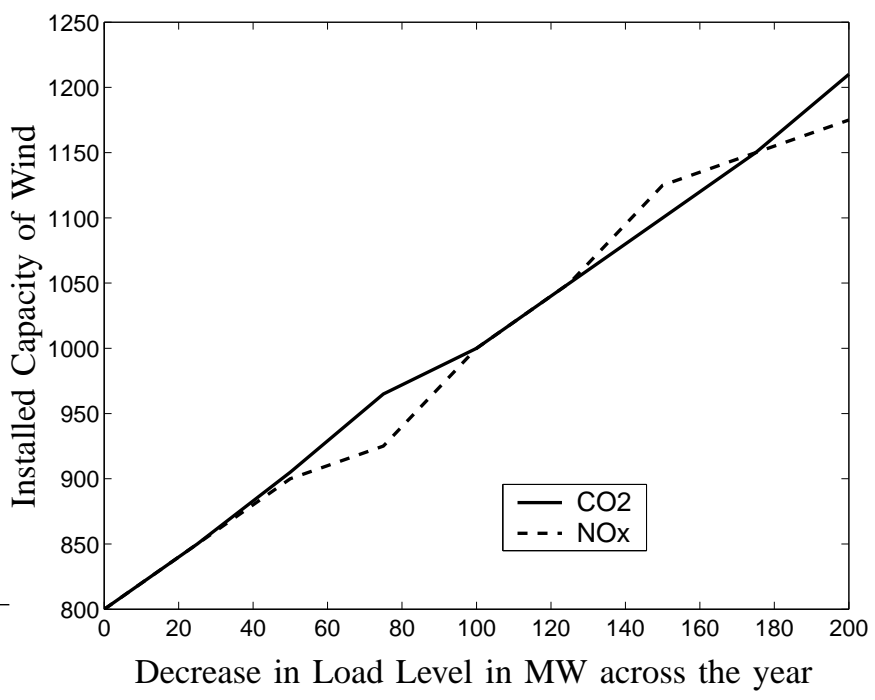

Fig. 9. Comparison of equivalent load reduction and wind generation installation

From Fig. 9 it can be seen that even a small reduction in the load offers substantial emission savings over wind generation. For example, a 50MW reduction in the load offers the same $\mathrm{CO}_{2}$ and $\mathrm{NO}_{\mathrm{X}}$ emission savings as a $100 \mathrm{MW}$ increase in the installed wind capacity. It has been shown that the smoothing of demand variance (from peak hours to off-peak hours) may have a detrimental effect on $\mathrm{CO}_{2}$ and $\mathrm{SO}_{2}$ emissions [7], however, this is only significant when the majority of plant is coal or oil fired. Since this is not the case in Ireland, a short term policy promoting the reduction in system demand through energy efficiency and consumer awareness may prove both more economical and more emission efficient than a short term policy promoting large scale investment in wind generation.

\section{CONClusion}

Although the results in this paper are based on the Irish electricity system they are indicative of any system with large penetrations of wind generation. Wind generation operated in a system which incorporates wind generation forecasts in its dispatch decisions (the forecasted approach) provides superior emission reduction benefits over a system which simply accommodates wind generation when it is available (the fuelsaver approach). Considerable $\mathrm{CO}_{2}$ reductions are seen with increasing levels of installed wind capacity, however, to significantly reduce emissions of $\mathrm{SO}_{2}$ and $\mathrm{NO}_{\mathrm{X}}$ in Ireland, wind generation must be combined with alternative emission reduction measures such as emission taxes, an alteration in the treatment of peat fired plant or load reduction schemes.

\section{ACKNOWLEDGMENT}

The author gratefully acknowledge the contributions of Ronan Doherty, Michael O’Mahony, Garth Bryans, John Fitzgerald and ESB Powergen.

\section{REFERENCES}

[1] Directive 2001/77/EC of the European Parliament and of the Council, "The promotion of electricity produced from renewable energy sources in the internal electricity market," Available: www.europa.eu.int/scadplus/leg/en/lvb/l27035.htm, 2001.

[2] "Kyoto protocol to the united nations framework convention on climate change," Available: www.unfccc.int, 1992.

[3] Directive 2001/80/EC of the European Parliament and of the Council, "The limitation of emissions of certain pollutants into the air from large combustion plants, october 2001." Available: www.europa.eu.int, 2001.

[4] Directive 2001/81/EC of the European Parliament and of the Council, "National emission ceilings for certain atmospheric pollutants," Available: www.europa.int.eu, 2001.

[5] M. O'Mahony (ESB Power Generation), "Personal communication," Electricity Supply Board, Dublin, Ireland, 2004.

[6] ESB National Grid (Eirgrid), "Impact of wind power generation in ireland on the operation of conventional plant and the economic implications," Available: www.eirgrid.com, 2004.

[7] S. Holland and E. Mansur, "Is real time pricing green?: The environmental impacts of electricity demand variance," Centre for the Study of Energy Markets, University of California Energy Institute, vol. WP 136, 2004.

[8] B. Harris, "Conversion of sulphur dioxide to sulphur trioxide in gas turbine exhaust," Journal of Engineering for Gas Turbine and Power, vol. 112 , pp. 585-589, 1990.

[9] A. Cunningham, "The reduction of atmospheric pollutants during the burning of heavy fuel oil in large boilers," Journal of the Institute of Fuel, vol. 51, pp. 20-29, 1978.

[10] U. Kesgin, "Study on prediction of the effects of design and operating parameters on NOx emissions from a leanburn natural gas engine," Energy Conversion and Management, vol. 44, pp. 907-921, 2003.

[11] Energy Information Administration (EIA), "Electric power annual 2000," Available: www.eia.doe.gov, vol. II, 2000.

[12] P. Lightman and P. Street, "The chemistry and physics of heavy oil combustion," in The Heavy End of the Barrel-Future Trends in Oil Firing, Institute of Energy Symposium, The Institute of Energy, Portsmouth, England, 1981, pp. $44-55$.

[13] Energy Information Administration, "EIA energy glossary," www.eia.doe.gov, 2004.

[14] K. Li, S. Thompson, and J. Peng, "Modelling and prediction of NOx emission in a coal-fired power generation plant," Control Engineering Practice, vol. 12, pp. 707-723, 2003.

[15] O. Delabroy et al., "Passive and active control of NOx in industrial burners," Experimental Thermal and Fluid Science, vol. 16, pp. 64-75, 1998.

[16] A. Mansour, M. Benjamin, D. Straub, and G. Richards, "Application of macrolamination technology to lean, premix combustion," AMSE Journal of Engineering for Gas Turbines and Power, vol. 123, no. 4 , pp. 796-802, 2001.

[17] G. Cabot, D. Vauchelles, B. Taupin, and A. Boukhalfa, "Experimental study of lean premixed turbulent combustion in a scale gas turbine chamber," Experimental Thermal and Fluid Science, vol. 28, pp. 683690, 2004.

[18] P. Gardiner, H. Snodin, A. Higgins, and S. M. Goldrick, "The impacts of increased levels of wind penetration on the electricity systems of the republic of ireland and northern ireland," Garrad Hassan and Partners Limited, Glasgow, Tech. Rep. 3096/GR/04, Feb. 2003.

[19] Department of the Enterprise Trade and Investment, "A study into the economic renewable energy resource in northern ireland and the ability of the electricity network to accommodate renewable generation up to 2010," Available: www.energy.detini.gov.uk, 2003. 
[20] R. Doherty, E. Denny, and M. O'Malley, "System operation with a significant wind power penetration," in IEEE Power Engineering Society General Meeting, Denver, Colorado, USA, June 2004.

[21] R. Doherty and M. O'Malley, "New approach to quantify reserve demand in systems with significant installed wind capacity," IEEE Transactions on Power Systems, vol. 20, no. 2, pp. 587-595, 2005.

[22] R. Doherty, G. Lalor, and M. O’Malley, "Frequency control in competitive electricity market dispatch,' IEEE Transactions on Power Systems (in press), 2005.

[23] PLEXOS for Power Systems - Electricity Market Simulation, www.draytonanalytics.com.

[24] ESB National Grid (Eirgrid), "Market and system data (download section)," Available: www.eirgrid.com, 2004.

[25] ESB National Grid, "Forecast statement 2004-2010 - transmission system operator ireland," Available: www.eirgrid.com, 2004.

[26] Transmission System Operator Ireland, "Generation adequacy report: 2004 - 2010," Available: www.eirgrid.com, 2003.

[27] Commission for Energy Regulation - Ireland, "Impact of the EU emissions trading scheme on the irish electricity market - CER/03/284," Available: www.cer.ie, 2003.

[28] Department of Communications Marine and Natural Resources (Ireland)- Statutory Instrument No 217 of 2002, "Electricity regulation act 1999 - (public service obligations) order 2002," Available: www.dcmnr.gov.ie, 2002.

[29] Energy Policy Statistical Support Unit of Sustainable Energy Ireland (SEI), "Energy in ireland 1990 - 2002: Trends,issues and indicators," Available: www.sei.ie, 2003.

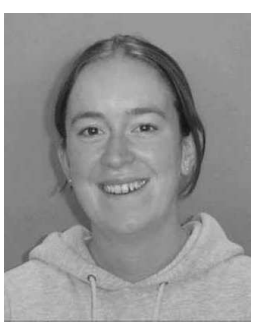

Eleanor Denny received a B.A. degree in Economics and Mathematics and a M.B.S. degree in Quantitative Finance from University College Dublin in 2000 and 2002, respectively. She is currently studying for a $\mathrm{Ph}$. D. degree in the Electricity Research Centre, University College Dublin with research interests in emissions, the economics of embedded generation and wind generation integration.

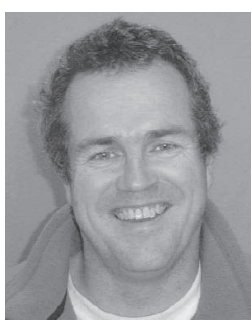

Mark O'Malley received B.E. and Ph. D. degrees from University College Dublin in 1983 and 1987, respectively. He is currently a Professor in University College Dublin and director of the Electricity Research Centre with research interests in power systems, control theory and biomedical engineering. $\mathrm{He}$ is a senior member of the IEEE. 